\title{
La propiedad plural de los establecimientos de alojamiento turístico: la figura del condo- -hotel en la legislación autonómica
}

\author{
Alejandro Román Márquez \\ Universidad de Sevilla, (España)
}

\begin{abstract}
Resumen: En el presente estudio se analizan las diferentes regulaciones autonómicas que existen actualmente de la figura del condo-hotel, las cuales presuponen en todo caso la admisión explícita de la propiedad plural de los establecimientos de alojamiento turístico. Con ocasión de dicho análisis se plantearán una serie de cuestiones problemáticas en torno a los diferentes modelos de propiedad, los principios de unidad de explotación y uso turístico exclusivo aplicados a esta figura, así como los nuevos modelos alternativos surgidos para paliar su escasa rentabilidad como producto de inversión inmobiliaria.
\end{abstract}

Palabras Clave: Condo-hotel; Condominio; Combo-hotel; Propiedad plural; Establecimientos de alojamiento turístico.

\section{Plural ownership of tourist accommodation establishments: condo-hotels in regional law}

Abstract: In the present study the different regional regulations that currently exist for the status of condo-hotel are analyzed from the perspective of explicit admission of the plural ownership of tourist accommodation establishments. A number of issues with respect to different patterns of ownership arise from this analysis, with the operating principles of management unity and exclusive tourist use applied to this figure, as well as new and alternative models that have emerged to alleviate their low profitability as real estate investments.

Keywords: Condohotel; Condominium; Combo-hotel; Plural ownership; Tourist accommodation establishments.

\section{Introducción: concepto de condo-hotel y utilidad de esta figura.}

La figura del condominium hotel o condo-hotel no es nueva. Tiene su origen en la década de los años setenta del siglo veinte, pero el éxito obtenido durante la última década ${ }^{1}$ ha devuelto a la actualidad, si cabe con más fuerza que en su alumbramiento, a estafigura ${ }^{2}$. El concepto de condo-hotel -condotel e, incluso, hotecondo-se origina por la fusión de las palabras "condomino" (término utilizado en Estados Unidos para referirse a la propiedad horizontal) y "hotel", y parte de una concepción del establecimiento hotelero que atiende esencialmente a la estructura de la propiedad inmobiliaria sobra la que se asienta. Se puede definir al condo-hotel como aquel edificio destinado a alojamiento hotelero cuya propiedad está dividida horizontalmente, y en el que sus propietarios ceden contractualmente la gestión a un solo operador a cambio de una contraprestación económica, con la posibilidad además de utilizar su propiedad de forma privativa durante un periodo de tiempo determinado al año ${ }^{3}$. Desde una perspectiva cronológica, los particulares adquieren la propiedad sobre una o varias porciones del establecimiento de alojamiento turístico susceptibles de explotación económica -que reciben el nombre de unidades de alojamiento- y la titularizad conjunta -pro indivisa- de los elementos comunes del inmueble. A continuación, encomiendan a un operador privado, mediante un contrato de gestión hotelera, la explotación de la unidad o unidades de alojamiento de su propiedad, de forma que ambos -propietario

Profesor Doctor del Departamento de Derecho Administrativo de la Universidad de Sevilla, Espana; E-mail: aroman2@us.es 
y gestor-obtienen una rentabilidad económica, cuyo mecanismo de reparto quedará igualmente fijado en el citado contrato de gestión hotelera. Finalmente, se puede incluir en el acuerdo que el propietario utilice personalmente alguna de sus unidades de alojamiento durante un tiempo determinado, de forma que durante estos periodos el propietario pueda alojarse en su propiedad como un huésped más, disfrutando de los servicios e instalaciones que ofrece el establecimiento de alojamiento turístico en las condiciones pactadas en el contrato de gestión hotelera.

La retribución a la empresa explotadora del establecimiento se puede materializar a través de una cuantía fija -canon de explotación - pactada en el contrato de cesión, pero también es posible que se fije en función de los resultados de explotación, de forma que los ingresos derivados del uso de las unidades de alojamiento se repartan, en los porcentajes acordados, entre propietarios y explotador ${ }^{4}$. Esta última modalidad permite a las partes compartir tanto los riesgos como los beneficios de esta asociación. Y por lo que respecta a los gastos, la empresa gestora del establecimiento deberá sufragar los derivados directamente de su explotación turística (personal, limpieza, mantenimiento, publicidad, tributos vinculados con la actividad empresarial, etc.), siendo el resto a cargo de los propietarios (grandes reparaciones, reformas, seguros y tributos vinculados con la propiedad del inmueble y con los beneficios obtenidos por la explotación de su unidad de alojamiento), si bien existe libertad de pactos en esta materia.

Las razones por las que la figura del condo-hotel ha vuelto a cobrar actualidad son variadas, destacándose por los analistas del sector la caída de la rentabilidad hotelera, el crecimiento del turismo residencial, los planes de desinversión de activos por parte de algunas cadenas hoteleras y la entrada de nuevos inversores en el sector (Valls, 2007). Mediante esta figura, el sector turístico pretende atraer la inversión en segunda residencia, que en España procede fundamentalmente de ciudadanos nacionales de Estados miembros de la Unión Europea, y que pese a la crisis económica sufrida en los últimos años no ha dejado de crecer. Las ventajas de la utilización de este sistema de explotación turística tienen naturaleza bidireccional. En primer lugar, permite al empresario turístico acceder a un inmueble para su explotación hotelera sin realizar las inversiones que conlleva su construcción, de forma que puede iniciar la gestión del mismo sin necesidad de desembolso económico o financiación externa. Desde este punto de vista la ventaja para el empresario hotelero es innegable, pero no difiere fundamentalmente de la alcanzada con modalidades contractuales de larga tradición en el ámbito civil, como el arrendamiento de industria (art. 1.546 y ss. del Código Civil) ${ }^{5}$. Por lo que respecta a los inversores ${ }^{6}$, la ventaja para ellos también es innegable pues, habida cuenta de que las segundas residencias se utilizan generalmente durante un pequeño espacio de tiempo al año ${ }^{7}$, su cesión al empresario turístico permite obtener rendimientos económicos de éstas en aquellos momentos en los que no son utilizadas por su propietario. Pero no solamente los adquirentes de segundas residencias de naturaleza vacacional pueden encontrar ventajas en esta figura. También para determinadas personas que por diversos motivos (familiares o laborales, fundamentalmente) deban viajar recurrentemente a algún destino puede llegar a resultar menos oneroso adquirir en propiedad un espacio en el que pernoctar durante sus desplazamientos, de forma que el gasto dedicado a este menester pueda ser recuperado mediante su transformación en una inversión de naturaleza inmobiliaria ${ }^{8}$. Esta última posibilidad resulta merecedora de consideración no solo por parte de las personas físicas, sino también de las jurídicas, pues para determinadas empresas puede resultar más ventajoso alojar a sus trabajadores en espacios de su propiedad -cuya inversión puede ser amortizada durante el tiempo en que no sean usados por éstos a través de su explotación turística-, que sufragar individualmente cada una de estas pernoctaciones.

\section{La regulación del condo-hotel en España. El presupuesto esencial de los condo-hoteles en la normativa turística autonómica: propiedad horizontal versus copropiedad.}

En el ordenamiento jurídico español no existe una regulación jurídica del contrato de condo-hotel. Se trata de un contrato de naturaleza atípica, en el que se adquiere la propiedad sobre un bien inmueble en régimen de propiedad horizontal, con las limitaciones necesarias para hacer posible su explotación mercantil y, al mismo tiempo, se cede la explotación de este bien a una empresa explotadora durante un periodo de tiempo determinado, con la posibilidad de que su propietario lo aproveche gratuita y personalmente durante el tiempo pactado con la empresa explotadora (González Cabrera, 2015) ${ }^{9}$. No existe, por tanto, un contrato típico denominado como tal por el ordenamiento jurídico español ni, consecuentemente, un régimen jurídico propio y diferenciado del mismo.

Lo que sí existe es una regulación de la figura del condo-hotel desde el punto de vista de la oferta alojativa regulada por la normativa turística autonómica. Varios legisladores autonómicos han consi- 
derado necesario prever expresamente en sus leyes sectoriales la posibilidad de organizar la propiedad y explotación de los establecimientos de alojamiento turístico conforme a la estructura del condo-hotel. Las normas que contienen tales previsiones son, por orden cronológico, la Ley 13/2011, de 23 de diciembre, del Turismo de Andalucía (en adelante LTA) ${ }^{10}$; la Ley 8/2012, de 19 de julio, del Turismo de las Illes Balears (en adelante LTIB); y la Ley 2/2013, de 29 de mayo, de Renovación y Modernización turística de Canarias (en adelante LRMTC). Para el legislador autonómico, la necesidad de prever de forma explícita la posibilidad de que la propiedad de los establecimientos de alojamiento turístico pueda constituirse de forma horizontal debe buscarse en el desarrollo de estas modalidades turísticas en los mercados internacionales así como en el aumento de su demanda en buena parte del territorio nacional como consecuencia de la capacidad reconocida a los condo-hoteles para sostener y revitalizar la demanda turística ${ }^{11}$. Igualmente, su previsión expresa en la legislación turística viene originada por su consideración como fórmula esencial para atraer la inversión, contribuir a la desestacionalización alargando la temporada turística, mejorar la calidad de los establecimientos y de sus servicios, así como de los servicios complementarios; actualizar la planta hotelera, aumentar los niveles de empleo en el sector, además de modernizar y reconvertir la industria turística en general ${ }^{12}$.

El presupuesto fáctico esencial en torno al cual las legislaciones autonómicas construyen sus regulaciones de la figura del condo-hotel no es otro que la forma de organizar la propiedad de los inmuebles explotados bajo este régimen. Para el legislador autonómico el condo-hotel es una figura que tiene como requisito fundamental que la propiedad de sus unidades de alojamiento y elementos comunes pertenezca a una multiplicidad de propietarios. A partir de este criterio elemental pueden construirse dos nociones de condo-hotel, ambas atendiendo a esta configuración plural de su propiedad. Una primera noción estaría conformada por las leyes turísticas andaluza y balear, que prescinden de apelativos como "condo-hotel", "condominio" o similares, y califican a esta modalidad turística directamente por la forma concreta de organizar su propiedad plural, esto es, como "establecimientos en régimen de propiedad horizontal" (art. 42.1 LTA) o "establecimientos de alojamiento turístico coparticipados o compartidos" (art. 35 LTIB). En el primer caso, el andaluz, existe una plena identificación entre la denominación de esta clase de establecimientos de alojamiento turístico y la forma de organizar su propiedad: la propiedad horizontal. En el segundo caso -balear-, no existe plena identificación, pues el apelativo "coparticipado" o "compartido" presupone una titularidad plural, pero no la forma exacta de organizarse ésta. En cualquier caso, y a pesar de esta denominación -que figura en el encabezamiento del precepto de referencia para esta figura y en varios lugares de la norma-, el legislador balear conceptualiza esta modalidad, al igual que sucede en la Ley andaluza, a partir de la naturaleza horizontal de su propiedad. Por consiguiente, en este primer grupo de regulaciones el presupuesto esencial es que la propiedad de los activos que le sirven de sustento material esté organizada en régimen de propiedad horizontal, lo cual va a predeterminar, en parte, su régimen jurídico, pues, en todo lo no regulado directamente por las leyes turísticas autonómicas -norma principal en esta materia- habrá que acudir a la normativa reguladora de la propiedad horizontal ${ }^{13}$-normativa subsidiaria-, por ejemplo, en materia de obligaciones de los propietarios, quórum necesario para la toma de decisiones, obras a realizar en la misma, sostenimiento y conservación del inmueble, órganos de gobierno, adquisición y enajenación de la propiedad, etc.

Los legisladores andaluz y balear parecen haber renunciado a utilizar cualquier referencia al término condomino porque, a pesar de ser considerado por parte de la doctrina iusprivatista como equivalente a la propiedad horizontal (Rouanet Mora, 2002; Cobas Cobiella, 2014), se trata de un concepto ajeno a la tradición jurídica española en este concreto ámbito. Y por lo que respecta al término condo-hotel o similares, ambos legisladores prescinden del mismo por ser demasiado limitado, en el sentido de circunscribir esta figura a los establecimientos hoteleros, cuando en ambas legislaciones se permite la propiedad horizontal de establecimientos de alojamiento turístico en general, lo que incluye la modalidad hotelera, pero también los apartamentos turísticos, los alojamientos de turismo rural y cualquier otra modalidad alojativa que, por su naturaleza, pueda ser susceptible de división horizontal de su propiedad y cumpla con los requisitos de categorización exigidos por la legislación turística. Con respecto a esta última exigencia, el legislador andaluz exige que los establecimientos sean de una categoría mínima de cuatro estrellas o de tres llaves, y el balear exige tres estrellas superior o tres llaves (arts. 42.1 LTA y 35.1 LTIB).

En ambas regulaciones se plantea la duda de qué quiere decir el legislador autonómico al señalar que los inmuebles dedicados a establecimientos de alojamiento turístico se pueden constituir en régimen de propiedad horizontal o "figuras afines". ¿Cuáles son tales figuras afines a la propiedad horizontal? ¿Está pensando el legislador en otras formas de propiedad plural del inmueble? Se trataría en tal caso de la copropiedad conjunta del inmueble en régimen de pro indiviso, en el sentido establecido 
por los artículos 392 y ss. del Código Civil (comunidades de bienes). La diferencia fundamental con la organización horizontal de la propiedad estará, por tanto, en que mientras que en ésta cada propietario lo es de una parte cierta, específica y singular del inmueble (en este caso, de una o varias unidades de alojamiento), con la única excepción de ciertos elementos comunes del mismo ${ }^{14}$; en el régimen de copropiedad o propiedad pro indiviso, los propietarios lo son con respecto de una fracción o porcentaje indiferenciado de la propiedad globalmente considerada, de modo que no es posible atribuir la propiedad de una unidad de alojamiento específica a un propietario concreto. Todos son, por tanto, dueños de la totalidad del inmueble, sin que sea posible la asignación de partes concretas del mismo a favor de los copropietarios. La copropiedad está sometida a un régimen jurídico propio y diferenciado del que regula la propiedad horizontal, sin embargo, en virtud del artículo segundo letra b) de la Ley 49/1960, de 21 de julio, sobre propiedad horizontal, estarán sometidos igualmentea esta Ley "[...] en lo relativo al régimen jurídico de la propiedad, de sus partes privativas y elementos comunes, así como en cuanto a los derechos y obligaciones recíprocas de los comuneros" cuando participen de las características de los inmuebles organizados conforme a la figura de la propiedad horizontal ${ }^{15}$, aunque no hubiesen otorgado el título constitutivo de la propiedad horizontal. Otra figura que parece encajar en el concepto de figura "afín" a la propiedad horizontal son los denominados complejos inmobiliarios privados -conocidos comúnmente como "urbanizaciones privadas"- y que están sometidos asimismo, como regla general, a la Ley de Propiedad Horizontal (arts. segundo letra c) y veinticuatro) ${ }^{16}$.

Precisamente la segunda de las nociones planteadas al inicio de este epígrafe, conformada en solitario por la ley canaria, además de ser la única que utiliza el término "condominio" para referirse a los condo-hoteles -hoteles en régimen de condominio los califica la LRMTC, lo que restringiría la admisibilidad de esta figura exclusivamente a los establecimientos hoteleros ${ }^{17}$, , también es la única que prevé de forma expresa que la titularidad dominical de estos establecimientos pueda encontrarse "dividida en diferentes unidades registrales" (es decir, en régimen de propiedad horizontal), pero también "en participaciones indivisas sobre una finca", admitiendo explícitamente que la propiedad de los establecimientos de alojamiento turístico pueda ser objeto de copropiedad. Esta circunstancia podría justificar el calificativo de la primera de las nociones planteadas como estricta-desde el punto de vista de la organización de su propiedad plural, al admitir únicamente su forma horizontal-, frente a una noción del mismo calificable como amplia -por admitir, junto a la organización horizontal de la propiedad, la copropiedad sobre el mismo- ${ }^{18}$. Sin embargo, esta clasificación pierde su sentido y utilidad si se mantiene, como se ha hecho supra, que la referencia que hacen las leyes andaluza y balear a las citadas "figuras afines" abre la puerta a otras formas de propiedad plural de los establecimientos de alojamiento turístico, concretamente a la copropiedad sobre éste, así como a los denominados "complejos inmobiliarios privados". Y es que parece razonable entender que en todos los casos el legislador autonómico admite diferentes formas de organizar la propiedad plural sobre el inmueble, diferenciándose únicamente en el reconocimiento explícito o no de esta posibilidad.

El legislador canario ahonda un poco más en las posibilidades organizativas del condo-hotel, permitiendo expresamente que "[...] los copropietarios [puedan] constituir una sociedad mercantil con personalidad jurídica independiente de la que ostenta la titularidad dominical, en su caso, con objeto de que gestione la explotación del hotel [...]" (art. 30.2 b) LRMTC). Además, se habilita a la sociedad explotadora para que pacte a su vez la cesión de su actividad a favor de terceros, los cuáles se subrogarían en las obligaciones gestoras de la cedente ${ }^{19}$. En este caso el legislador canario no se está refiriendo a la forma de organizar la propiedad del inmueble, sino exclusivamente a la forma de organizar la gestión del mismo, en este caso mediante la creación de una persona jurídica - una sociedad mercantil-cuyo objeto es precisamente la explotación de aquél. Sin embargo, al plantear esta posibilidad el legislador canario desliza -conscientemente o no- una cuestión de gran relevancia. Señala éste que la sociedad mercantil que los copropietarios creen para la gestión del condo-hotel tendrá personalidad independiente de la que ostente "en su caso" la titularidad dominical del inmueble. De este modo, se está reconociendo la posibilidad de que los copropietarios del condo-hotel cedan la gestión a una sociedad mercantil creada $e x$ profeso y cuyos titulares son ellos mismos; pero también, de forma implícita, se habilita a estos mismos copropietarios para que, si lo estiman conveniente, constituyan -previamente- una sociedad mercantil a la que traspasarán la titularidad del inmueble. Se da entrada así, y esto es muy importante, a la posibilidad de que la propiedad del establecimiento sea no solamente plural-organizada en forma de propiedad horizontal o copropiedad-, sino también individual -de naturaleza societaria-, pues en el caso de que los copropietarios cedan la titularidad del establecimiento a una sociedad mercantil, su propietaria será exclusivamente ésta, y no lo copropietarios, que a partir de dicho momento dejarán de ser los dueños del establecimiento para serlo de la fracción del patrimonio social que en cada caso les 
corresponda. Es decir, pasarían de ser dueños del establecimiento a dueños de la sociedad mercantil propietaria del mismo. En tal caso se quebraría la identificación entre propiedad plural y condo-hoteles, que había constituido el presupuesto esencial para la construcción de esta figura en la legislación turística autonómica ${ }^{20}$. Posteriormente, el propio ejecutivo canario admitiría expresamente una forma de propiedad individual de naturaleza societaria en esta materia, al señalar en su Decreto 85/2015, de 14 de mayo, por el que se aprueba el Reglamento de la Ley de renovación y modernización turística de Canarias, que la propiedad de los condo-hoteles puede organizarse en régimen de propiedad cooperativa, es decir, pertenecer a una sociedad cooperativa (artículo 33.2 de esta norma).

Para finalizar, llama la atención el hecho de que el legislador canario solamente permita expresamente esta última posibilidad a los propietarios pro indiviso, cuando nada obsta desde el punto de vista jurídico para que los propietarios horizontales pueden constituir sociedades mercantiles, tanto para la gestión del condo-hotel como para ostentar la titularidad dominical del establecimiento en su conjunto. No es posible encontrar en el texto de esta Ley ningún argumento que permita conocer la razón de tal limitación. En cualquier caso, y al hilo de esta laguna, pueden ponerse de manifiesto otras omisiones carentes de justificación por parte del legislador canario, el cual, por ejemplo, considera uso residencial de las unidades de alojamiento cuando en el contrato de cesión a la empresa explotadora se otorguen "reservas de uso" a los copropietarios por un periodo superior a seis meses (art. 30.2 c) LRMTC) ¿Por qué únicamente a los copropietarios? ¿No se considera uso residencial si la reserva se hace a favor de los propietarios horizontales? Y continúa señalando que, del mismo modo, se considerará uso residencial el uso efectivo -real- de las unidades de alojamiento por los propietarios durante un periodo superior al señalado ¿Y sí el uso efectivo se hace por parte de los copropietarios? ¿En tal caso no se consideraría uso residencial? Lo irrazonable de tal distinción hace pensar en un desliz del legislador canario, que utiliza como sinónimos ambos términos cuando no lo son -y cuando él mismo se ha ocupado de dejar patente su diferencia al utilizar ambos conceptos para identificar formas distintas de organizar la propiedad-, por lo que puede presumirse que ambas previsiones afectan tanto a copropietarios como a los propietarios de las unidades de alojamiento en régimen de propiedad horizontal. Lo mismo sucede al regular el contenido del documento informativo exigible para acceder a la condición de propietario en uno de estos inmuebles (art. 30.2 d) LRMTC). En este caso, la ley canaria señala que en él deberán consignarse "[...] las demás condiciones que deban establecerse en la escritura para la que se adquiera la condición de copropietario, [...], obviando que la condición de propietario en régimen horizontal también puede adquirirse -realmente formalizarse- a través de escritura pública ${ }^{21}$.

\section{El principio de unidad de explotación y de uso turístico exclusivo. La tradicional irrele- vancia de la propiedad de los inmuebles sujetos a explotación turística.}

Las legislaciones turísticas autonómicas en general, y las analizadas en estas páginas en particular, recogen dos principios esenciales relativos a la explotación de los establecimientos de alojamiento turístico. El primero de ellos es el denominado principio de unidad de explotación ${ }^{22}$, que obliga a que cada establecimiento sea gestionado por una única persona, que será el titular de su explotación, y sobre la que recaerá la responsabilidad administrativa derivada de su funcionamiento ${ }^{23}$. Este principio excluye la posibilidad, por tanto, de que alguna o algunas de las unidades alojativas del edificio o edificios que conforman el establecimiento de alojamiento turístico sean explotadas por personas o entidades diferentes a la que ostenta la titularidad de su explotación. Vinculado con este principio, si bien se trata de un principio diferente, el principio de uso turístico exclusivo implica la afectación a la prestación del servicio de alojamiento turístico de la totalidad de las unidades de alojamiento integrantes de una edificación o edificaciones -0 de partes independientes y homogéneas ocupadas por cada establecimiento-, sin que resulte admisible que alguna o algunas de las unidades de alojamiento sean dedicadas a un uso no turístico, como el residencial o cualquier otro ${ }^{24}$. Ambos principios se aplican a la figura del condo-hotel como establecimientos de alojamiento turístico que $\operatorname{son}^{25}$.

El legislador autonómico ha mostrado tradicionalmente una indiferencia absoluta con respecto a la titularidad y naturaleza -individual, pro indivisa, horizontal, societaria- de la propiedad de los establecimientos de alojamiento turístico ${ }^{26}$. El principio de unidad de explotación turística atiende exclusivamente a la gestión de estos establecimientos, sin afectar a la titularidad dominical de los mismos. Es decir, se exige que una única persona o ente -entiéndase persona jurídica- explote la totalidad del establecimiento, pero quién sea su propietario no es -o mejor dicho, no era- en absoluto relevante, quedando su determinación y régimen jurídico en el ámbito de las normas generales sobre la 
propiedad inmobiliaria, propias del Derecho común o privado, y fuera por tanto de la esfera turística. Por tal razón, era perfectamente posible la admisión de propietarios de establecimientos de alojamiento turístico en régimen horizontal o pro indiviso sin necesidad de darles cabida de forma expresa en la normativa turística, de forma que lo que hoy se conoce como condo-hoteles era una figura amparada por la legislación preexistente (y, por tanto, admitida actualmente en aquellas Comunidades Autónomas que no regulan esta figura, salvo previsión expresa en contrario). La inclusión de previsiones expresas al respecto obedece a razones extrajurídicas -como el fomento de esta figura, eliminando las incertidumbres que pudieran amedrentar a los eventuales inversores-, pues tanto la posibilidad de que las unidades alojativas de un mismo establecimiento pertenezcan a diferentes propietarios, ya sea individual o conjuntamente; como la obligación de cederlas en su conjunto a una única empresa gestora -principio de unidad de explotación-, han estado amparadas por el Derecho común y previstas en la legislación turística autonómica, respectivamente, desde hace ya bastante tiempo.

Además, tanto anteriormente como en la actualidad, es posible que los propietarios -pro indiviso $\mathrm{u}$ horizontales- sean tanto personas físicas como jurídicas, incluyendo por tanto a las sociedades mercantiles, pues las legislaciones turísticas autonómicas tampoco han establecido limitaciones a este respecto. Éstas utilizan expresiones como "personas propietarias", "personas cesionarias" o "propietarios adquirentes", las cuales no predeterminan la naturaleza física o jurídica de los propietarios. En este sentido, la legislación canaria no innova al prever, como se señaló anteriormente, que la titularidad de las unidades de alojamiento -de todas o respecto de algunas de éstas-pueda ser asumida por una sociedad mercantil, pues nada obstaba, conforme al Derecho común y ante el silencio de la normativa turística, para que una persona jurídica fuese ya propietaria de una o varias unidades de alojamiento. Tampoco al prever que los copropietarios - personas físicas o jurídicas- constituyan una sociedad mercantil con la única finalidad de atribuirle la titularidad dominical de todo el establecimiento, convirtiéndose a partir de ese momento en copropietarios no ya del inmueble, sino de la sociedad mercantil propietaria de éste, pues ello también es admitido con carácter general por el ordenamiento jurídico. La única novedad estaría en exigir la separación entre esta sociedad mercantil, propietaria del inmueble -de existir, puesto que es únicamente una posibilidad, pero no una obligación-, y la sociedad mercantil creada a su vez por los copropietarios para la gestión del establecimiento, las cuales deben ser independientes entre sí. Esta separación parece a todas luces injustificada, pues para cumplir con el principio de unidad de explotación basta con que ésta esté encomendada a una única empresa explotadora, sin que la concreta titularidad de esta empresa tenga ninguna relevancia al efecto, es decir, sin importar que los titulares de ambas sociedades coincidan o no. Las leyes andaluza y balear exigen igualmente una separación entre propiedad -horizontal-y explotación -empresa gestora-, pero en este caso tal disgregación está justificada, pues entre los diferentes propietarios de las unidades de alojamiento organizados horizontalmente no existe ninguna ligazón que les permita gestionar conjuntamente el establecimiento (su único nexo común es que todos son propietarios en un mismo inmueble, pero nada más), por lo que se ven obligados a apoyarse en una estructura unitaria que permita explotar el establecimiento en su conjunto. Esta necesidad se materializa en la obligación legal, para todos los propietarios, de ceder la gestión de su propiedad a favor de una única empresa explotadora, y así cumplir con el principio de unidad de explotación. Necesidad que tampoco existiría en el supuesto de que los diferentes propietarios -o copropietarios- del establecimiento hubiesen atribuido la titularidad dominical completa a una sociedad mercantil por ellos creada, pues ésta está habilitada para explotar el establecimiento en su conjunto, respetando el principio de unidad de explotación, sin necesidad de ceder su gestión a otra sociedad mercantil independiente de la primera, tal y como exige el legislador canario. Se trata esta última, por tanto, de una exigencia carente de justificación en el principio de unidad de explotación, pues nada obsta a que una sociedad mercantil que posee la titularidad de un establecimiento de alojamiento turístico lo explote, es más, suele ser lo habitual en el caso de grandes establecimientos hoteleros.

Por lo que respecta al principio de uso turístico exclusivo, se completa generalmente con el principio de compatibilidad de usos turísticos, que admite la presencia, en el mismo inmueble, de distintos tipos de establecimientos de alojamiento turístico (arts. 45 LTA o 36 LTIB) ${ }^{27}$. En relación a este principio, debe tenerse en cuenta que el condo-hotel no es en sí mismo una modalidad de establecimiento de alojamiento turístico, sino una forma de organizar y explotar el mismo, que puede revestir -con los requisitos señalados supra-varias modalidades (establecimientos hoteleros, apartamentos turísticos, establecimientos de alojamiento rural, etc.), por lo que resulta perfectamente posible la coexistencia, en un mismo inmueble, de condo-hoteles y de otros establecimientos de alojamiento turístico tradicionales, sean del tipo que sean, pues la propiedad del inmueble nunca va a presuponer una modalidad 
turística concreta. Es decir, el principio de compatibilidad no afecta -ni positiva ni negativamente- a los condo-hoteles como concepto, pues está pensado para diferentes modalidades de establecimientos turísticos, teniendo como referencia sus características de uso, no su propiedad. La única excepción a esta afirmación está constituida, como se ha advertido, por la legislación canaria, que identifica expresamente la figura del condo-hotel con los establecimientos hoteleros y, más concretamente, con los hoteles (art. 30.1 LRMTC), por lo que su compatibilidad con otros establecimientos de alojamiento turístico quedará restringida a lo que disponga expresamente la legislación canaria ${ }^{28}$.

\section{Elementos comunes del régimen jurídico del condo-hotel en la normativa turística autonómica.}

A pesar de las divergencias expuestas en el epígrafe segundo de este estudio, relativas fundamentalmente a la forma de conceptuar la propiedad de los condo-hoteles -y en cualquier caso más teóricas que reales, como se ha podido comprobar-, las regulaciones autonómicas de esta figura también presentan una serie de elementos coincidentes, lo que permite construir su régimen jurídico común:

a) Compromiso conjunto, por parte de los propietarios de las unidades de alojamiento, de cesión de todas éstas -incluyendo las zonas comunes del inmueble- a favor de una única empresa explotadora (arts. 42.2 b) LTA, 35.4 b) LTIB y 30.2 b) LRMTC). El plazo mínimo de vigencia se fija con carácter general en diez años, salvo en el caso de la legislación balear, que no establece ningún plazo al efecto. Por el contrario, esta última exigirá en solitario al ente explotador que acredite su habilitación para explotar la totalidad del establecimiento en su conjunto o, en su caso, de la totalidad de los elementos o unidades de alojamiento en los que se encuentre dividido, mediante la aportación del título jurídico en el que se acredite el compromiso de cesión a su favor realizado por los propietarios de las unidades de alojamiento (art. 35.5 LTIB).

Si el inmueble está organizado en régimen de propiedad horizontal, el quórum necesario para la toma de decisiones en materia de usos será la unanimidad. Y ello porque los usos del mismo se encuentran recogidos en los estatutos de la comunidad de propietarios ${ }^{29}$, y su modificación exige la unanimidad de éstos $^{30}$. En relación a esta cuestión pueden plantearse diversas situaciones: $a$ ) si los promotores ${ }^{31}$ del inmueble incluyeron el uso turístico en el momento de otorgar el título constitutivo y los estatutos de la propiedad no será necesario un nuevo acuerdo al respecto, porque todos los adquirentes de las unidades de alojamiento conocían, en el momento de acceder a su propiedad, el destino del mismo -condo-hotel-, por lo que no es necesario pronunciarse nuevamente a este respecto, más allá de la elección concreta de la empresa explotadora (para lo que bastará mayoría simple $\mathrm{e}^{32}$; $b$ ) si en los estatutos de la comunidad de propietarios no se prohíbe expresamente el uso turístico del inmueble, hará falta unanimidad de los propietarios para su explotación en régimen de condo-hotel, y no porque sea necesario modificar dicho estatuto ${ }^{33}$, sino porque el principio de uso turístico exclusivo no admite unidades de alojamiento no dedicadas a la actividad turística, y el uso o destino de cada propiedad no puede ser impuesto por el resto (ni siquiera por mayoría cualificada) ${ }^{34}$; y c) si el uso turístico estuviese expresamente prohibido en los estatutos de la comunidad de propietarios (porque así lo decidiesen originariamente los promotores del inmueble o, con posterioridad, los miembros de la comunidad de propietarios), la explotación en régimen de condo-hotel exigirá la modificación de aquéllos, para lo que es necesario, como se ha señalado, la unanimidad de los propietarios del edificio.

$\mathrm{Si}$, por el contrario, la propiedad de las unidades de alojamiento fuese de naturaleza pro indivisa, por pertenecer de forma conjunta a los diferentes copropietarios, no sería necesaria unanimidad de los comuneros, pues el Código Civil dispone que los acuerdos se toman por mayoría -simple- de los partícipes $^{35}$. La copropiedad de las unidades de alojamiento facilita, en principio, la decisión relativa a su dedicación como establecimiento de alojamiento turístico explotado en régimen de condo-hotel ${ }^{36}$. Sin embargo, como se ha señalado, cuando los inmuebles reúnen todas las características de la propiedad horizontal -descritas en el artículo 396 del Código Civil- serán aplicables a éstos las reglas de la Ley 49/1960, de 21 de julio, sobre propiedad horizontal, en todo lo relativo al régimen jurídico de la propiedad, y ello con independencia de que el inmueble esté sometido formalmente al régimen de la copropiedad por no haberse otorgado el título constitutivo de la propiedad horizontal (artículo segundo letra b) de la Ley de Propiedad Horizontal). Esta es la razón por la que la legislación canaria (art. 30.2 e) A) LRMTC.) impone a la copropiedad una regla propia de la propiedad horizontal, al señalar que la 
afección al uso turístico que realicen los "(co)propietarios" "no podrá ser alterad[a] salvo por decisión unánime" de éstos ${ }^{37}$.

En relación con estas cuestiones, algún autor (Massana Valés, 2007:17) advierte de la posibilidad de que los promotores del inmueble se reserven la propiedad de algunas de las unidades de alojamiento de forma que puedan garantizar la continuidad de su dedicación al uso turístico y la toma de otras decisiones importantes, como la elección de la empresa explotadora, con la finalidad de que sean ellos mismos los elegidos para este menester, y así garantizar no solo el control de la propiedad inmobiliaria, sino también de su explotación económica. Se trata de una posibilidad materializada en Estados Unidos, país en el que existen establecimientos de alojamiento turístico -hoteles, fundamentalmente- en los que sus promotores se han reservado la propiedad de una parte del mismo -un ala o varias plantas, con sus correspondientes unidades de alojamiento-, de forma que coinciden sobre la misma propiedad y gestión (al ser los promotores del inmueble también sus explotadores) (Canalis, X: 2005) ${ }^{38}$. En el caso de inmuebles en régimen de propiedad horizontal o "afines", recuérdese que el uso turístico puede ser incluido por el promotor en el título constitutivo de la comunidad de propietarios, de forma que sería suficiente con mantener la propiedad de una sola de estas unidades para bloquear la unanimidad exigida para modificar su uso.

Ambas situaciones generan dos cuestiones estrechamente relacionadas: por un lado la admisibilidad o no en un mismo establecimiento de unidades de alojamiento pertenecientes a un único propietario (el promotor) y a diferentes propietarios; y por otro, la admisibilidad o no de la compatibilidad entre propiedad y gestión del establecimiento (en caso de que el promotor que retiene la propiedad de una o varias unidades de alojamiento sea al mismo tiempo el explotador del establecimiento). En ambos casos la respuesta es idéntica: el legislador autonómico parece admitir ambas posibilidades. Con respecto a la primera, porque, como ya se ha señalado, al legislador le resulta indiferente quién sea el propietario concreto de las diferentes unidades de alojamiento y, además, tampoco establece cupos máximos de unidades de alojamiento pertenecientes a un mismo propietario, por lo que resulta admisible que varias o incluso la mayoría de unidades de alojamiento pertenezcan a único propietario. Y con respecto a la segunda cuestión, resulta igualmente admisible pues si bien el legislador autonómico exige que se ceda la gestión de las diferentes unidades de alojamiento a una empresa explotadora, no reclama que la titularidad de ésta deba ser diferente a la de la propiedad del establecimiento objeto de explotación ${ }^{39}$. Es decir, siempre que se respeten los principios de unidad de explotación y de uso turístico exclusivo, la posibilidad de que los promotores se reserven la propiedad de una o varias unidades de alojamiento y se atribuyan a sí mismos su explotación -junto con el resto de las que componen el establecimiento- será admisible de acuerdo con la legislación autonómica.

b) Prohibición del uso residencial de las unidades de alojamiento por parte de sus propietarios (arts. 42.3 LTA, 35.6 LTIB y 30.2 c) LRMTC). Como señala la Ley andaluza, siempre deberá prevalecer la naturaleza mercantil y turística de las unidades de alojamiento sobre cualquier otro destino ${ }^{40}$. Pero esto no significa que las unidades de alojamiento no puedan ser disfrutadas de forma privativa por sus propietarios, sino que a partir de un determinado umbral de uso el legislador autonómico considera que excede de lo admisible dentro de la naturaleza del condo-hotel, convirtiéndose en una mera segunda residencia ${ }^{41}$. Dicho umbral de uso tiene carácter temporal, no pudiendo ser superior a dos meses al año en Andalucía y Baleares, y a seis meses en el caso de Canarias. Se proscribe no solamente el uso -entiéndase gratuito- de las unidades alojativas por parte de sus propietarios, sino también -en el caso de Andalucía y Baleares- su uso en "condiciones ventajosas" respecto de las ofrecidas al resto de usuarios (v.gr. aplicando tarifas inferiores a las generales o incluyendo servicios extraordinarios ${ }^{42}$, presumiéndose además la existencia de uso residencial cuando en el contrato de cesión de la gestión de las unidades de alojamiento a la entidad explotadora se reserve a los propietarios su uso por un periodo de tiempo superior al establecido como límite máximo por cada Comunidad Autónoma.

Algunas Administraciones públicas han mostrado cierto recelo en relación a la autorización de condo-hoteles en sus territorios derivado de la posibilidad de cambio de uso del inmueble en su conjunto, esto es, de todas sus unidades de alojamiento, de forma que un establecimiento de alojamiento turístico se convierta, por decisión de sus propietarios, en un inmueble de uso residencial. Hasta tal extremo han llegado estos reparos que algunas Administraciones públicas deniegan la autorización para la instalación y apertura de condo-hoteles en suelos de uso turístico con la finalidad de evitar que, si sus propietarios deciden transformar su uso turístico en residencial, no queden enclavados en áreas urbanas de uso turístico (Valls, 2007; Munar Bernat, 2010: 327). Sin embargo, las Administraciones turísticas deben tener en cuenta que los usos de la 
propiedad inmobiliaria están determinados no solamente por la voluntad de sus propietarios, sino por el resto de previsiones establecidas por el ordenamiento jurídico, entre las que destaca el planeamiento urbanístico. Por ello, y con independencia de la voluntad de sus propietarios, si un inmueble está ubicado en un área de uso turístico exclusivo no podrá dejar de dedicarse a esta actividad -con las posibilidades y requisitos que en cada caso se establezca-, pues así lo exige la normativa urbanística, y viceversa.

Así lo advierte expresamente el legislador canario, el cual dispone que para desafectar un inmueble del uso turístico es necesario decisión unánime de sus propietarios, pero con el requisito inexcusable de que el "planeamiento [urbanístico] lo permita" (art. 30.2 e) A) LRMTC) ${ }^{43}$. Además, cuando los titulares de los establecimientos turísticos incumplan el deber de atenerse al uso turístico del establecimiento, el Decreto 85/2015, de 14 de mayo, por el que se aprueba el Reglamento de la Ley de renovación y modernización turística de Canarias, habilita expresamente a la Administración autonómica para, sin perjuicio de la sanción que proceda, imponer dicho deber, concediendo para ello un plazo no inferior a un año (al objeto de que durante éste se lleven a cabo las actuaciones necesarias para "reconducir" tal situación) (arts. 31.2 y 32 del Decreto) ${ }^{44}$.

c) Inscripción del uso turístico de cada unidad de alojamiento en el Registro de la Propiedad (arts. 42.2 LTA, 35.4 LTIB y 30.2 e) LRMTC) ${ }^{45}$. Las regulaciones autonómicas de la figura del condo-hotel exigen que se anote marginalmente en la hoja registral de cada unidad de alojamiento su afección al uso turístico, de forma que cualquier adquirente pueda conocer dicha limitación de su uso. La protección del adquirente amparado por el artículo 34 de la Ley Hipotecaria ${ }^{46}$ se extiende de este modo al uso turístico del inmueble por decisión expresa del legislador turístico autonómico. Igualmente, deberá inscribirse en el Registro de la Propiedad la cesión de uso a favor de la empresa explotadora ${ }^{47}$, incluyendo -en el caso de Canarias- las condiciones de tal cesión.

d) Obligación de entrega, a cargo de los promotores de inmuebles explotados en régimen de condo-hotel ${ }^{48}$, de un "documento informativo" a los adquirentes de unidades de alojamiento (arts. 42.4 LTA, 35.7 LTIB y 30.2 b) LRMTC). Dicha entrega deberá hacerse con anterioridad a la venta ${ }^{49} \mathrm{de}$ las unidades de alojamiento y deberá contener, de forma exhaustiva, toda la información sobre la afectación del inmueble al uso turístico, así como demás condiciones previstas en los preceptos legales reguladores de esta figura. A estas previsiones, la ley balear añade a la información obligatoria la relativa a los riesgos asumidos por los adquirentes en caso de incumplimiento o insolvencia de la empresa explotadora y la posible derivación de sus responsabilidades a los propietarios adquirentes. Por su parte, el legislador canario, congruente con la posibilidad de constituir condo-hoteles en régimen de copropiedad, exige que en el citado documento queden reflejadas todas aquellas condiciones que deban establecerse en la escritura para que los compradores adquieran la condición de copropietarios ${ }^{50}$. Por último, y en relación a la naturaleza de este documento informativo, tanto la norma andaluza como la balear consideran que tiene carácter de oferta vinculante, por lo que su aceptación por el comprador producirá efectos jurídicos sin necesidad de contar con una manifestación de voluntad expresa por parte del vendedor (al considerarse que ésta ya está contenida en propio documento informativo).

\section{Algunas cuestiones heterogéneas previstas en la normativa turística autonómica en relación a la figura del condo-hotel.}

La primera cuestión que merece ser tratada en este epígrafe es la relativa al origen o nacimiento del condo-hotel, es decir, el momento a partir del cual un inmueble puede ser explotado conforme a este particular régimen jurídico. Esta cuestión es abordada de forma diversa por la legislación autonómica. Así, mientras que la Ley andaluza no hace referencia alguna al momento habilitado para la constitución del condo-hotel, la Ley balear señala expresamente que "[s]e podrán constituir en régimen de propiedad horizontal o figuras afines los establecimientos existentes o de nueva creación de alojamiento turístico [...]" (art. 35.1 LTIB) ${ }^{51}$, lo que permite, además de la creación de condo-hoteles, la transformación en condo-hoteles de establecimientos de alojamiento turístico preexistentes. La Ley canaria admite igualmente ambas posibilidades, al regular tanto "[...] las plazas de alojamiento promovidas bajo esta modalidad [...] como [...] la reconversión a esta modalidad de cualquier establecimiento de alojamiento existente [...]" (art. 30.2 a) LRMTC) ${ }^{52}$. Se admite, por tanto, con carácter general en la legislación turística autonómica tanto la creación ex profeso de establecimientos de alojamiento turístico para su explotación 
en régimen de condo-hotel como la adaptación a este régimen de establecimientos de alojamiento turístico preexistentes. Posibilidades que deben considerarse extensibles a los condo-hoteles radicados en el territorio de la Comunidad Autónoma andaluza, al no excluirse expresamente -en ninguno de los dos sentidos- en su legislación turística. Por la misma razón, debe aceptarse con carácter general la transformación en condo-hoteles de inmuebles preexistentes de naturaleza residencial, para lo cual será necesario la previa adaptación de las unidades de alojamiento a las exigencias de la normativa turística y la concesión de la pertinente autorización de actividad turística (o instrumento de policía equivalente, como la declaración responsable o la comunicación), todo ello sin olvidar los requisitos para el cambio de uso de un inmueble expuestos supra. En tal sentido, y al hilo de la posibilidad genérica de que establecimientos de alojamiento turístico extrahoteleros se conviertan en hoteleros, el Decreto canario 85/2015 dispone que, en el caso de que no se garantice fehacientemente por la totalidad de los propietarios en documento público inscrito en el Registro de la Propiedad la unidad de explotación "futura" y "permanente", el nuevo establecimiento podrá constituirse en comunidad de propietarios (art. 13.2 c). Sin entrar a valorar la utilidad del cambio de régimen dominical como mecanismo para garantizar la unidad de explotación, lo relevante de este precepto es la confirmación, ahora por parte del ejecutivo canario, de que es posible la conversión de establecimientos de alojamiento turístico preexistentes en condo-hoteles.

Continuando con otras cuestiones reguladas de forma desigual por la legislación turística autonómica, encontramos una serie de requisitos de naturaleza heterogénea que se añaden a los analizados en el epígrafe anterior. Así, mientras que la Ley andaluza exige que los establecimientos de alojamiento turístico que pretendan acceder al régimen de condo-hotel deben contar con una categoría mínima de cuatro estrellas o de tres llaves (art. 42.1 LTA), la Ley balear suma a este requisito la apertura al público durante un mínimo de seis meses al año, con la obligación añadida de superar, en el transcurso de dos años desde la presentación de la declaración responsable de inicio de actividad bajo esta forma de explotación, los "planes de modernización" y "de calidad" previstos por la normativa balear vigentes en tal momento, incluyendo -en su caso- la reforma integral del establecimiento (art. 35.3 LTIB) ${ }^{53}$. La Ley canaria, por su parte (art. 30.2 a) LRMTC), exige que, en el caso de que se trate de nuevos establecimientos promovidos bajo esta modalidad, deban contar previamente con las autorizaciones administrativas previas de sus plazas de alojamiento en una serie de supuestos excepcionales previstos en su artículo 4.3 LRMTC. Por el contrario, si se trata de la transformación de un establecimiento de alojamiento preexistente, exigirá que ésta venga precedida de la correspondiente renovación o rehabilitación. Finalmente, las leyes autonómicas establecen algunos deberes de información (art. 35.8 LTIB), así como ciertas previsiones de naturaleza sancionadora específicamente referidas a la figura del condo-hotel (art. 42 apartados 1, 2, 7, 8 y 9 LTA) ${ }^{54}-$.

\section{El condo-hotel como inversión: algunas señales negativas en relación a su capacidad para proporcionar una rentabilidad razonable a sus propietarios. La reinvención del condo-hotel como segunda residencia "remunerada".}

La dimensión indubitablemente económica del condo-hotel, en el cual ha prevalecido tradicionalmente su utilidad como instrumento de inversión sobre su potencialidad residencial, justifica el decir algunas palabras sobre esta cuestión en este último epígrafe de este trabajo y, cómo no, sobre las implicaciones jurídicas derivadas de ciertas figuras nacidas al amparo de las nuevas tendencias del mercado. Como se adelantó en el epígrafe introductorio, el condo-hotel es un instrumento atractivo tanto para los promotores turísticos como para los inversores privados. Además de las ventajas mencionadas en su momento, permite al adquirente amortizar su inversión, y al ser propietario de un inmueble -en régimen de propiedad horizontal o copropiedad-podrá disponer de él cuando tenga necesidad de ello o así lo estime conveniente mediante su enajenación onerosa (compraventa) o gratuita (donación), además de la posibilidad de constituir sobre la misma aquellos derechos reales compatibles con su naturaleza, como el usufructo. Precisamente la posibilidad de constituir garantías reales sobre el inmueble constituye otro de los atractivos para los inversores, los cuales pueden acceder a la propiedad de unidades de alojamiento sin necesidad de contar con los recursos económicos necesarios, a través de un préstamo con garantía hipotecaria para su adquisición (González Cabrera, 2015: 794-795). Por todas estas razones el condo-hotel ha recibido, fundamentalmente en Estados Unidos y otros países del ámbito anglosajón, una gran atención por parte de los medios especializados, llegando a constituirse en el auténtico producto estrella de muchas operaciones de marketing inmobiliario. 
Sin embargo, precisamente en aquellos países en los que se ha construido un mayor número de condo-hoteles se empiezan a vislumbrar algunas señales negativas en relación a su capacidad para generar beneficios razonables para los inversores. Los analistas en la materia advierten en este sentido que, si bien sigue siendo un instrumento atractivo para los promotores inmobiliarios, ha perdido gran parte de su capacidad de atracción para los eventuales compradores, fundamentalmente por una serie de causas que se pueden resumir en las siguientes (Santora, 2010; King, 2013; Salomon, 2014): en primer lugar, la crisis económica global ha provocado una contracción del crédito bancario, de forma que los particulares tienen menos facilidades para acceder al capital necesario para adquirir las unidades de alojamiento, lo que a su vez ha provocado una bajada en sus precios de adquisición, redundando negativamente en las cantidades de que disponen los promotores para construir el inmueble y sus equipamientos ${ }^{55}$. En segundo lugar, el aumento de la oferta alojativa ha hecho caer el precio de la noche de hotel, disminuyendo la rentabilidad de las unidades alojativas ${ }^{56}$. En tercer lugar, el pequeño tamaño del mercado de compraventa de unidades de alojamiento de "segunda mano" hace que la demanda de éstas sea pequeña, lo que baja su eventual precio de venta una vez que el comprador quiere prescindir de su propiedad. En cuarto lugar estaría el coste de las plazas no ocupadas. Mientras que los analistas consideran que una habitación de hotel debe ganar un dólar cada noche por cada mil invertidos en su construcción o remodelación, y permanecer ocupadas entre el sesenta y el setenta por ciento del tiempo; la ganancia media en varios destinos anglosajones es cero con novecientos cincuenta y dos dólares por noche, estando ocupadas un cuarenta y dos por ciento del tiempo, lo que muestra la difícil amortización de estas inversiones. En quinto lugar, el aumento progresivo del precio que los propietarios de las unidades de alojamiento pagan por disfrutar de los servicios e instalaciones del hotel cuando hacen un uso residencial de éstas, pues ha sido habitual que en el acuerdo de compraventa se incluyesen unas tarifas reducidas -e incluso gratuitas- de estos servicios e instalaciones con el objetivo de mejorar el atractivo de estas inversiones, pero pasado el plazo estipulado - entre uno y dos años suele ser lo habitual- los precios suben hasta niveles que hacen inviable económicamente su disfrute ordinario, lo que habría desincentivado en gran medida la compra de unidades alojativas para su disfrute prioritariamente residencial. En sexto y último lugar, y como consecuencia de las anteriores circunstancias, estaría la exigua tasa interna de retorno de la inversión, situada entre el uno y el dos por ciento, lejos de la cifra del cuatro al seis por ciento habitual en estos países para una inversión inmobiliaria ordinaria.

Como alternativa a la escasa rentabilidad de la inversión en condo-hoteles los promotores estadounidenses han creado una nueva figura, que congrega en un mismo edificio o complejo de edificios un establecimiento hotelero tradicional -desde el punto de vista de su propiedad, al pertenecer a un único titular- y viviendas residenciales, de forma que los propietarios de estas últimas puedan disfrutar de los servicios e instalaciones del hotel, al tener acceso a éstos a cambio de unas tarifas estipuladas en el contrato de adquisición de las viviendas (pues su promotor es el mismo que el promotor y/o explotador del establecimiento hotelero) (Santora, 2010) ${ }^{57}$. Estos falsos condo-hoteles pueden denominarse, a falta de un calificativo de uso generalizado, como combo-hoteles, pues son una combinación, en un mismo espacio, de hoteles tradicionales y de viviendas de uso residencial (las cuales, a su vez, suelen estar constituidas como comunidades de propietarios, esto es, en régimen de propiedad horizontal). Las ventajas de esta figura estarían en la mayor facilidad de acceso a la financiación por parte de los particulares para la adquisición de las viviendas, pues elimina la tradicional reticencia existente en el mercado anglosajón a financiar propiedades de uso mixto (como son las unidades de alojamiento en los condo-hoteles: turístico y residencial). También permite a sus propietarios disfrutar de la calidad de los servicios e instalaciones vinculados con un establecimiento hotelero (servicio de habitaciones y de restauración, recepcionista, gimnasio, piscina, sauna, aparcamiento con servicio de aparcacoches, terraza, lavandería, guardería, botones, zonas ajardinadas, instalaciones deportivas, etc.) pero sin soportar ninguna restricción temporal a su uso residencial ${ }^{58}$, y con unos costes de mantenimiento considerablemente menores (Rinomato, 2016) ${ }^{59}$. También en el momento de su enajenación existen ventajas, pues la experiencia ha demostrado que su venta es más rápida -y a un precio más alto- que con respecto a una unidad de alojamiento de un condo-hotel. Las desventajas estarían en la imposibilidad de obtener un rendimiento económico cuando el inmueble no sea utilizado por su titular, pues aunque compartan servicios e instalaciones con el establecimiento hotelero, no forman parte del mismo, siendo meras viviendas de uso residencial y no unidades de alojamiento, por lo que no es posible su explotación turística como habitación de hotel. Además, el disfrute de los servicios e instalaciones dependerán en última instancia de que el hotel se encuentre en funcionamiento, por lo que surgirá un grave problema para los residentes de estos complejos en el caso de que la gestión del hotel quede interrumpida por cualquier causa. 
La admisibilidad de esta figura por parte de nuestro ordenamiento jurídico es ciertamente problemática, siendo necesario analizar dos cuestiones diferentes en relación a la misma: la compatibilidad de usos -turístico y residencial- sobre una misma parcela, y la posibilidad de que los servicios e instalaciones de los establecimientos de alojamiento turístico puedan ser disfrutados por personas no alojadas en éstos. La primera cuestión debe ser resuelta atendiendo a la normativa urbanística, pues es ésta la que regula los usos del suelo, y generalmente no suele admitir la compatibilidad entre el uso residencial y el turístico en una misma parcela por las incomodidades que para los residentes conlleva la actividad turística (fundamentalmente por los ruidos ocasionados por una actividad sujeta a unos horarios diferentes a los del residente habitual) (Sola Teyssiere, 2007-a y 2007-b). Dicha incompatibilidad de usos es tan evidente para algunos legisladores autonómicos que consideran necesario que sea su propia normativa turística la encargada de prohibir expresamente su concurrencia sobre un mismo espacio ${ }^{60}$. En cuanto a la segunda de las cuestiones planteadas, en torno a la posibilidad de que las instalaciones y servicios de los establecimientos de alojamiento turístico puedan ser usados por personas distintas a sus huéspedes, también presenta dificultades pues no está resuelta explícitamente por la normativa turística autonómica. Y es que, con carácter general, ésta se limita a exigir que ciertas infraestructuras de determinados establecimientos de alojamiento turísticos sean de uso exclusivo para sus clientes y empleados (ascensores y escaleras, fundamentalmente ${ }^{61}$ ), pero nada más. Para tratar de resolver esta difícil cuestión es necesario diferenciar entre instalaciones y servicios de los establecimientos turísticos. En relación a las primeras, el principio de uso turístico exclusivo parece excluir su disfrute por parte de personas ajenas al establecimiento, esto es, no alojadas en el mismo, con la finalidad de conformar un ambiente homogéneo dentro de sus instalaciones (esto es, una clientela de un nivel socioeconómico similar), si bien es cierto también que la generalidad de leyes turísticas que regulan esta cuestión se refieren a la exclusividad del uso turístico respecto de las unidades de alojamiento, sin hacer mención expresa en ningún momento al resto de instalaciones (restaurante, aparcamiento, instalaciones deportivas, sauna, etc.), por lo que no es posible afirmar categóricamente la prohibición de su uso conjunto por parte de sus huéspedes y de personas ajenas al establecimiento de alojamiento turístico ${ }^{62}$. En relación a los servicios que prestan los establecimientos de alojamiento turístico (servicio de habitaciones, lavandería, limpieza, mantenimiento, etc.), su ampliación a inmuebles residenciales colindantes no debería estar prohibida por la normativa turística al no afectar al principio de uso turístico exclusivo, pues como se ha mantenido la finalidad de este principio es la conformación de una concurrencia o ambiente homogéneo dentro las instalaciones del establecimiento, al que no afecta -ni positiva ni negativamente- la extensión de sus servicios fuera de aquéllas. Como conclusión a la cuestión de la admisibilidad o no de la figura del combo-hotel en el ordenamiento jurídico español, deberá analizarse la normativa y planeamiento urbanísticos para conocer si la compatibilidad de usos turístico y residencial sobre una misma parcela es admisible en el territorio en cuestión. Solamente cuando la respuesta a esta primera cuestión sea positiva podrá analizarse la admisibilidad del uso compartido de servicios e instalaciones entre los establecimientos de alojamiento turístico y los inmuebles de uso residencial que conforman el combo-hotel.

Volviendo al ámbito económico, a pesar de las señales negativas comentadas, a partir de 2014 se asiste a una razonable recuperación del mercado de condo-hoteles en el ámbito anglosajón (Benson, 2014) ${ }^{63}$, debido fundamentalmente a un cambio de enfoque por parte de sus promotores. Y es que éstos se han dado cuenta de que los condo-hoteles son más atractivos para los compradores como segunda residencia "remunerada" que como mera inversión inmobiliaria. Existe un gran mercado compuesto por personas que prefieren pasar sus periodos de ocio en una segunda residencia de su propiedad, pero sin las molestias que dicha propiedad comporta (mantenimiento, limpieza, acceso a servicios, etc.). Entre este grupo destacan los denominados Winters (Greene, 2006): personas jubiladas que residen durante los meses fríos en zonas templadas, como Florida y California en Estados Unidos o España y Portugal en el caso de Europa. Este grupo valora de forma destacada la comodidad que aporta residir en un inmueble de su propiedad (con lo que tiene ello de acogedor) y que además cuenta con una gran cantidad de servicios de fácil acceso (lo que representa una gran ventaja habida cuenta la media de edad de estas personas). Por otro lado están aquellas personas que persiguen una alta calidad de vida (lifestyle enthusiasts), además del prestigio asociado al hecho de poseer una "parte" de un establecimiento hotelero de lujo, como ocurre, por ejemplo, como los condo-hoteles promovidos por cadenas hoteleras de prestigio -como Ritz-Carlton o Barceló-, diseñados por reconocidos arquitectos y decorados por conocidas firmas de moda e, incluso, de vehículos de alta gama (Benson, 2014). Todo ello ilustraría cómo el nuevo cliente preferencial de las promociones de condo-hoteles no es ya el mero inversor que busca únicamente obtener un beneficio económico de su compra, sino personas que valoran su adquisición por otras circunstancias diferentes a las meramente económicas, y ello porque "la gente se está empezando a dar cuenta, una vez más, de que estar de vacaciones incluso cuando estás en tu propia casa es una magnífica forma de vivir" (Benson, 2014) ${ }^{64}$. 


\section{Reflexión final.}

A partir de lo expuesto a lo largo de este trabajo puede concluirse que la figura del condo-hotel era perfectamente admisible por la generalidad de leyes turísticas autonómicas sin necesidad de su previsión expresa -y, por tanto, lo es también en aquellas Comunidades Autónomas que no han regulado esta figura, salvo previsión expresa en contrario-, pues la propiedad de los establecimientos dedicados al alojamiento turístico no había sido objeto de atención por partedel legislador autonómico en relación con esta materia, al tratarse de una cuestión ajena al ámbito turístico. Bastaba, por tanto, con acudir a las normas generales sobre propiedad inmobiliaria para admitir la propiedad plural en el ámbito turístico. Ninguna limitación establecía -ni establece- la normativa turística autonómica al respecto, pues debe tenerse muy presente que el principio de unidad de explotación no implica en ningún caso un hipotético principio de unidad de propiedad. Además, resulta cuanto menos controvertido el hecho de que el legislador autonómico pueda utilizar la competencia que la Constitución le atribuye en materia turística para regular un asunto de Derecho común como es el régimen jurídico general de la propiedad inmobiliaria, sea o no de uso turístico. Sin embargo, sí que puede considerarse acertado, por parte del legislador turístico autonómico, el hecho de prever y admitir expresamente la propiedad plural -horizontal o pro indiviso- de los establecimientos de alojamiento turístico con la finalidad exclusiva de aportar seguridad jurídica a los eventuales inversores en condo-hoteles, de forma que se disipen los reparos y dudas en torno a esta figura. En cualquier caso, si se parte del aserto de que el legislador autonómico en ningún caso contradice o innova la regulación de una materia que escapa de su ámbito competencial, limitándose a evidenciar una posibilidad admitida con carácter general, debe concluirse que la regulación autonómica de la figura del condo-hotel no solo es oportuna por las razones apuntadas, sino respetuosa con el ordenamiento jurídico español.

Desde una perspectiva económica, parece clave, a la vista de los acontecimientos sucedidos en el mercado anglosajón, reorientar la figura del condo-hotel para que su naturaleza como producto de inversión deje paso a una naturaleza de "segunda residencia remunerada", de forma que aumente su atractivo ante eventuales compradores y pueda superarse el escollo que su escasa rentabilidad supone en el mercado actual.

\section{Bibliografía}

Benson, $\mathrm{P}$.

2014. "Investing in condo Hotels. Time to cash in on condo Hotels", 27 de mayo, disponible en http:// www.wealthdaily.com/articles/investing-in-condo-hotels/5180.

Butler, J., Braum, B. Y Maisnik, G.

2014. "Condo hotel revolution and resurgence: why developers are using "new breed" of condo hotels for financing. One "little" legal change has revolutionized and revitalizad condo Hotels", 30 de octubre, disponible en http://hotellaw.jmbm.com/new-breed-of-condo-hotels.html.

Canalis, X.

2005. "Condo-hoteles: oportunidades y mitos", en Editur. Semanario profesional del turismo, n 2.385, 25 de noviembre, p. 21.

Cobas Cobiella, $\mathrm{M}^{\mathrm{a}}$. E.

2014. "Condominio y comunidad de propietarios", en Comunidad de bienes, Reyes López, Mª . J. (Coord.) et al., Tirant Lo Blanch, pp. 85-114.

De Campos Vieira, R.

2015. "Brazil: deliberation on condo-hotels", en International Financial Law Review, 23 de abril, disponible en http://www.iflr.com/Article/3447514/Brazil-Deliberation-on-condo-hotels.html.

González Cabrera, I.

2013. "Los principios de unidad de explotación y de uso turístico exclusivo, requisitos favorecedores para la explotación del establecimiento alojativo en régimen de condohotel (pp. 777-801)", en I Foro Internacional de Turismo de Maspalomas Costa Canaria. Congreso internacional de destinos turísticos, competitividad y emprendimiento en tiempos de crisis, Benítez del Rosario, J. M., González Molina, A. y Breede Eyzaguirre, C. (Dirs.) et al., Universidad de Las Palmas de Gran Canaria.

González Cabrera, I.

2015. “Tiempo compartido y condohotel (pp. 191-213)", en Manual de contratación turística, Fluxá Franch, J. (Dir.) et al., Atelier. 
Greene, J.

2006. "Thinking for buying a condo hotel: here are 20 things you need to know", 6 de agosto, disponible en http://ezinearticles.com/?Thinking-of-Buying-a-Condo-Hotel?--Here-Are-20-Things-You-Need-to-Know!\&id=262086.

Hinojosa, V.

2015. mayo. "El condohotel como fórmula de inversión", en Hosteltur, n 248: 36-37.

Horno, C.

2007. "Luces y sombras del modelo del condo-hotel", en Condo-hoteles: nuevo modelo de desarrollo hotelero y su implantación práctica, CEHAT-Garrigues-THR, disponible en http://www.cehat.com/ frontend/cehat/CEHAT-Garrigues-Y-THR-Analizan-La-Formula-Condo-hoteles-vn2936-vst338.

King, R.

2013. "Condo-hotels: automatic returns, or so you think", 10 de julio, disponible en http://www.moneysense. ca/columns/condo-hotels-automatic-returns-or-so-you-think/.

López Letón, S.

2015. "Cualquiera puede comprarse una habitación de hotel", 30 de mayo, disponible en http://economia. elpais.com/economia/2015/05/28/vivienda/1432810420_732271.html.

Manso, M.

2011. "Condohotel, el híbrido que se impone", en 21 de julio, disponible en http://www.diariodemallorca. es/turismo/2011/07/21/condohotel-hibrido-impone/688589.html.

Marín García de Leonardo, T.

1996. El arrendamiento de industria, Tirant Lo Blanch.

Massana Valés, S.

2007. septiembre/octubre. "Distintas figuras jurídicas para los condohoteles", en TecnoHotel. Revista profesional para la hostelería y restauración, 433: 16.

Munar Bernat, P. A.

2010. "Aproximación a la figura del condohotel. Su incompatibilidad con la Ley de derechos de aprovechamiento por turnos", en Munar Bernat, P. A. (ed.) et al., Turismo residencial. Aspectos económicos y jurídicos, Dykinson.

Pizam, A.

2006. "Condominium hotels: a scorching hot lodging spot", en Hospitality management, 25: 167-169.

Polsky, S.

2013. "Which NYC condo-hotel is the best choice for condo-buyers", 27 de junio, disponible en http:// ny.curbed.com/2013/6/27/10226430/which-nyc-condo-hotel-is-the-best-choice-for-condo-buyers.

Prada Álvarez Buyilla, P.

2010. "La inscripción en el Registro de la Propiedad de los hoteles en condominio", en Munar Bernat, P. A. (ed.) et al., Turismo residencial. Aspectos económicos y jurídicos, Dykinson.

Ranieri, M.

2015. "The new ABCs of private placements: 506(b) y 506(c)", 11 de marzo, disponible en http://www. forbes.com/sites/mraneri/2015/03/11/the-new-abcs-of-private-placements-506b-and-506c/.

Rinomato, S.

2016. "Pros and cons of buying a "condo hotel" suite", 10 de febrero, disponible en http://canadaam. ctvnews.ca/real-estate/pros-and-cons-of-buying-a-condo-hotel-suite-1.2771819.

Rivera, A.

2008. "Time share y condo-hoteles ganan peso", Editur. Tendencias y economía en la nueva sociedad del ocio, 12: 32 .

Rogerson, J. A.

2011. "The changing all-suite hotel in South Africa: from "extended stay" to african condo hotel", en Tourism review international, 15: (1-2): 107-121.

Rouanet Mota, E.

2002. "Comunidad de propietarios. Finca en condominio", en Actualidad administrativa, 32: 965-969.

Salomon, A.

2014. "Real estate Q\&A: are condo Hotels a good investment?", 19 de abril, disponible en http://www. forbes.com/sites/zillow/2014/05/19/real-estate-qa-are-condo-hotels-a-good-investment/.

Santora, M.

2010. "Looks like a condo, acts like a hotel", en The New York Times, edición de Nueva York, 19 de septiembre de 2010, pp. RE1 y ss. 
Sanz Domínguez, C.

2006. "La autorización y clasificación de establecimientos hoteleros en el ordenamiento español", en Administración de Andalucía: Revista Andaluza de Administración Pública, 62: 143-200.

Sola Teyssiere, J.

2007-a. Ordenación territorial y urbanística de las zonas turísticas, Tirant Lo Blanch/Instituto Andaluz de Administración Pública, $2^{\mathrm{a}}$ edición.

Sola Teyssiere, J.

2007-b. "La necesidad de un tratamiento jurídico diferenciado del suelo de uso turístico", en Revista de Urbanismo y Edificación, 15: 99-122.

Sola Teyssiere, J.

2013. en Manual de Derecho Administrativo del Sector Turístico, Fernández Ramos, S. (Dir.) y Pérez Guerra, R. (Coord.) et al., Tecnos, pp. 119 y ss.

Tabakman, D.

2005. “iSe vienen los condo hoteles a la Argentina?”, 19 de septiembre, disponible en http://www. reporteinmobiliario.com/nuke/article602-se-vienen-los-condo-hoteles-a-la-argentina.html.

Valls, A.

2007. enero-febrero. "Condohoteles: una apuesta de futuro no exenta de riesgos", TecnoHotel. Revista profesional para la hostelería y restauración, 429: 12.

Warnken, J. Y Guilding, C.

2009. "Multi-ownership of tourism accommodation complexes: a critique of types, relative merits, and challenges arising", en Tourism management, 30: 704-714.

Wittenburg, G.

2014-b. "Canyon Ranch Miami Beach set for bankruptcy auction", 5 de julio, disponible en http://www. skyfiveproperties.com/blog/canyon-ranch-miami-beach-set-bankruptcy-auction/.

Wittenburg, K.

2014-a. "Are condo Hotels a smart investment?", 28 de agosto, disponible en http://www.skyfiveproperties. com/blog/condo-hotels-smart-investment/.

\section{Notas}

1 Comenzando este resurgimiento en el Estado norteamericano de Florida y extendiéndose posteriormente al resto del país. El interés por esta figura se reactiva a partir de una guía publicada por la SEC (Securities and Exchange Commission) que mostraba a promotores y compradores cómo participar en este tipo de iniciativas bajo el amparo de las leyes estadounidenses. Un nuevo impulso tendrá lugar en 2013, cuando se modifica el ordenamiento jurídico estadounidense con el objetivo de facilitar la comercialización de las unidades de alojamiento como productos de inversión. En tal sentido se aprobó la Rule 506(c) de la SEC, que autoriza el uso de medios publicitarios (public solicitation) para la captación de nuevos inversores, prohibidos hasta ese momento en el sector. Sobre esta materia vid. Butler, Braum y Maisnik (2014) o Ranieri (2015).

2 El condo-hotel, tras su alumbramiento en los Estados Unidos, se extendió rápidamente por algunos países del continente americano (México, Brasil, Costa Rica, Argentina, Uruguay, etc.) y otros del ámbito anglosajón, como Sudáfrica, Australia o Canadá. En España existen varios condo-hoteles, tanto en funcionamiento como en fase de construcción. Así, por ejemplo, la cadena Sol-Meliá tiene media docena de condo-hoteles en territorio español. Sobre la recepción y desarrollo del condo-hotel en España vid., ad exemplum, Rivera (2008: 32); Manso (2011) u Horno (2007). En relación a la implantación de la figura del condo-hotel en el continente americano, africano y Australia vid., ad exemplum, Pizam (2006); De Campos Vieira (2015); Tabakman (2005) o Rogerson (2011)

3 Para la confección de esta definición se ha tomado como base, completándola, la aportada por Valls (2007).

4 En Estados Unidos el reparto de beneficios por alquiler de la unidad de alojamiento se hace normalmente a partes iguales entre propietario y explotador, aunque el rango fluctúa entre el treinta y cinco y el sesenta por ciento (atendiendo al porcentaje de beneficios que percibe el propietario) (Greene, 2006).

5 Marín García de Leonardo (1996: 50) define el arrendamiento de industria como "[...] aquel negocio jurídico en virtud del cual se cede el uso o explotación de una empresa o industria a persona distinta del titular, por precio cierto y tiempo determinado, consagrando así una disociación entre la titularidad y el ejercicio o explotación de ella".

6 Para el análisis de la figura del condo-hotel desde una perspectiva inversora. Vid., además de los trabajos citados a lo largo de este estudio, Hinojosa (2015) o Salomon (2014).

$7 \quad$ El caso extremo de infrautilización de segundas residencias se produce en las estaciones de esquí, en las que el número de camas frías (plazas de alojamiento en viviendas de propiedad particular) supera habitualmente al de camas calientes (plazas de alojamiento pertenecientes a establecimientos hoteleros), y cuya utilización media apenas si supera la semana al año. En estaciones como Sierra Nevada (Granada), la relación entre camas frías y calientes llega a ser de 2,5 a 1. Este asunto fue objeto de atención por la Comisión especial de estudios sobre las medidas a desarrollar para evitar la despoblación de las zonas de montaña del Senado (Diario de sesiones, X legislatura, $\mathrm{n}^{\circ} 385$, sesión de 24 de noviembre de 2014, pág. 8 in fine), sin conclusiones específicas al respecto. 
8 El precio de adquisición de las unidades de alojamiento varía, naturalmente, en función de sus características y ubicación. A modo de referencia, una habitación de treinta y cinco metros cuadrados con baño en el Hotel Meliá Costa del Sol (Torremolinos, Málaga) puede adquirirse en el mercado de segunda mano por unos ciento veinte mil euros, y en el Hotel Guadalpín Banús (Marbella, Málaga), la habitación de setenta y seis metros cuadrados tiene un precio de venta de casi un millón y medio de euros. En el caso de la ciudad de Nueva York, los precios oscilan entre el millón de dólares por unidad del Trump Soho a los casi doce millones de dólares en The Mark. López Letón (2015) y Polsky (2013).

9 Así lo configura la profesora González Cabrera, para quien este contrato posee una naturaleza jurídica igualmente compleja, al combinar un contrato de compraventa sobre bienes inmuebles con, al menos, un contrato de cesión. En cualquier caso, reconoce el carácter mercantil de este contrato así como la consideración de consumidores y usuarios a los propietarios de las unidades de alojamiento tanto en su calidad de inversores como de usuarios de las mismas.

10 Cuyo antecedente directo estaba en el artículo 6.2 del Decreto 47/2004, de 10 de febrero, de establecimientos hoteleros de Andalucía (redactado conforme a la disposición final primera del Decreto 35/2008, de 5 de febrero, por el que se regula la organización y funcionamiento del Registro de Turismo de Andalucía), que dispone que "[e]n los supuestos de separación entre propiedad y explotación, asi como cuando la propiedad del establecimiento se encuentre en régimen de copropiedad, comunidad o similar, la entidad explotadora deberá acreditar, mediante certificación del Registro de la Propiedad, que el establecimiento en su conjunto y cada una de sus unidades registrales, cualquiera que sea la persona propietaria, quedan afectos a uso en régimen locativo de hotel u hotel-apartamento, conforme al régimen y condiciones de uso que les resulten aplicables".

11 Exposición de Motivos de la Ley del Turismo de Andalucía, in fine.

12 Exposición de Motivos (apartado VI) de la Ley de turismo balear. La Ley canaria no expone los motivos que le han llevado a incluir explícitamente la posibilidad de constitución de condo-hoteles y similares.

13 La Ley 49/1960, de 21 de julio, de propiedad horizontal; modificada recientemente por la Ley 8/2013, de 26 de junio, de rehabilitación, regeneración y renovación urbanas.

14 Sobre los que recae un derecho de propiedad indiferenciado a favor de todos los miembros de la comunidad de propietarios, en los términos fijados por los artículos 396 del Código Civil y 3 de la Ley 49/1960, de 21 de julio, de propiedad horizontal.

15 Concretamente, el artículo segundo letra b) de la Ley 49/1960, de 21 de julio, sobre propiedad horizontal, se remite a las características establecidas en el artículo 396 de Código Civil, relativo a las comunidades de bienes: "Los diferentes pisos o locales de un edificio o las partes de ellos susceptibles de aprovechamiento independiente por tener salida propia a un elemento común de aquél o a la vía pública podrán ser objeto de propiedad separada, que llevará inherente un derecho de copropiedad sobre los elementos comunes del edificio, que son todos los necesarios para su adecuado uso y disfrute, tales como el suelo, vuelo, cimentaciones y cubiertas; elementos estructurales y entre ellos los pilares, vigas, forjados y muros de carga; las fachadas, con los revestimientos exteriores de terrazas, balcones y ventanas, incluyendo su imagen o configuración, los elemento de cierre que las conforman y sus revestimientos exteriores; el portal, las escaleras, porterías, corredores, pasos, muros, fosos, patios, pozos y los recintos destinados a ascensores, depósitos, contadores, telefonías o a otros servicios o instalaciones comunes, incluso aquéllos que fueren de uso privativo; los ascensores y las instalaciones, conducciones y canalizaciones para el desagüe y para el suministro de agua, gas o electricidad, incluso las de aprovechamiento de energía solar; las de agua caliente sanitaria, calefacción, aire acondicionado, ventilación o evacuación de humos; las de detección y prevención de incendios; las de portero electrónico y otras de seguridad del edificio, así como las de antenas colectivas y demás instalaciones para los servicios audiovisuales o de telecomunicación, todas ellas hasta la entrada al espacio privativo; las servidumbres y cualesquiera otros elementos materiales o jurídicos que por su naturaleza o destino resulten indivisibles [....]".

16 Si bien el artículo veinticuatro número cuatro de esta Ley admite que estos complejos se organicen conforme a otras formas jurídicas admitidas en derecho -como la copropiedad/comunidad de bienes-, en cuyo caso "[...] les serán aplicables, supletoriamente respecto de los pactos que establezcan entre sí los copropietarios, las disposiciones de esta Ley, con las mismas especialidades señaladas en el apartado anterior".

17 Por lo que podría haber utilizado, sin problema alguno, el calificativo condo-hotel o similar.

$18 \mathrm{Si}$, por el contrario, se atendiese a las categorías de establecimientos hoteleros susceptibles de propiedad plural, entonces la noción estricta correspondería a la legislación canaria (que únicamente admite establecimientos hoteleros) y la noción amplia a las leyes andaluza y balear (por admitirla, con carácter general, en cualquier establecimiento de alojamiento turístico, con los requisitos y naturaleza señalados).

19 Produciéndose en tal caso una subcontratación de la explotación del establecimiento a favor de un tercero.

20 En relación con esta cuestión, la admisibilidad o no de que la propiedad de los establecimientos de alojamiento turístico sea ostentada por una persona jurídica -y sus variantes- será analizada en el epígrafe siguiente.

21 El legislador canario llega a utilizar el término “(co)propietario" (art. 30.2 e) A) LRMTC), de difícil comprensión e, incluso, dudosa admisibilidad en lengua castellana.

22 Un análisis de este principio desde la óptica del Derecho mercantil puede encontrase en González Cabrera (2013: 777-801). Desde una perspectiva administrativista, Sola Teyssiere (2013: 119 y ss).

23 Así lo configura, por ejemplo, la legislación turística andaluza (art. 41 LTA), que exige, además, que la empresa explotadora acredite ante la Administración turística la titularidad de la propiedad u otros títulos jurídicos que la habiliten para la explotación del establecimiento, debiendo estar previamente inscrita en el Registro de Turismo de Andalucía. Por su parte, la ley balear excluye expresamente del principio de unidad de explotación a los usos secundarios compatibles con la actividad principal, que podrán ser prestados por personas o entidades distintas del titular de la explotación del establecimiento (art. 33.6 LTIB).

24 Posibilidad admitida legalmente en Estados Unidos, como se verá en el último epígrafe de este trabajo.

25 Con respecto al primero, está previsto en los artículos 41 y 42.1 LTA, 33 LTIB y 38 a 43 de la Ley 7/1995, de 6 de abril, de Ordenación del turismo de Canarias. El principio de uso turístico exclusivo está regulado en los artículos 41.2 LTA, 33.2 LTIB y 38.2 de la Ley 7/1995, de 6 de abril, de Ordenación del turismo de Canarias.

26 Para una primera aproximación sobre las formas de estructurar la propiedad de un condo-hotel vid. Massana Valés (2007). 
27 Sin embargo, el principio de compatibilidad de usos no es absoluto, pues las leyes turísticas autonómicas exigen que se trate de establecimientos de alojamiento turístico de similar naturaleza (por ejemplo, hoteles, hoteles-apartamentos y apartamentos turísticos) y categoría (mismo o parecido número de estrellas o de llaves).

28 Vid. a este respecto la Ley 7/1995, de 6 de abril, de ordenación del turismo de Canarias (art. 32.1) y el Decreto canario 142/2010, de 4 de octubre, por el que se aprueba el Reglamento de la Actividad Turística de Alojamiento y se modifica el Decreto 10/2001, de 22 de enero, por el que se regulan los estándares turísticos (art. 10).

29 Art. 5 párrafo tercero de la Ley 49/1960, de 21 de julio, de propiedad horizontal. Sin embargo, y aunque no sea lo habitual, no es imprescindible fijar tales usos en los estatutos de la comunidad de propietarios, al no ser exigido de forma obligatoria por esta Ley, sino como mera posibilidad.

30 Que, a su vez, representen el total de las cuotas de participación. Art. 17.6 de la Ley 49/1960, de 21 de julio, de propiedad horizontal.

31 Entendiéndose por promotor “[...] cualquier persona, física o jurídica, pública o privada, que, individual o colectivamente, decide, impulsa, programa y financia, con recursos propios o ajenos, las obras de edificación para sí o para su posterior enajenación, entrega o cesión a terceros bajo cualquier título" (artículo 9.1 de la Ley 38/1999, de 5 de noviembre, de Ordenación de la Edificación).

32 Art. 17.7 de la Ley 49/1960, de 21 de julio, de propiedad horizontal.

33 La jurisprudencia admite todos aquellos usos no prohibidos expresamente por los estatutos (y, obviamente, por el Ordenamiento Jurídico). V.gr. sentencias del Tribunal Supremo (Sala de lo Civil) de 24 de octubre de 2011 (recurso ${ }^{\circ}$ $527 / 2008$, fundamento de derecho tercero), y de 25 de junio de 2013 (recurso $n^{\circ} 76 / 2011$, fundamento de derecho tercero); entre otras.

34 Derivado del art. 3 a) de la Ley 49/1960, de 21 de julio, de propiedad horizontal.

35 Que, a su vez, representen la mayor cantidad de los intereses que constituyan el objeto de la comunidad (art. 398 del Código Civil), es decir, de la cuota o porcentaje de la propiedad. Por lo tanto, las mayorías no se componen de unidades de alojamiento, sino de cuotas o porcentajes de la propiedad, calculados en metros cuadrados sobre el total, al igual que sucede en la propiedad horizontal.

36 Si bien tiene los inconveniente derivados de la posibilidad de ejercer la acción de división de la cosa común en cualquier momento y por cualquiera de los copropietarios, amén de los derechos de adquisición preferente previstos por el Código Civil.

37 Solamente en aquéllos casos en los que se admita la sujeción a las reglas de la copropiedad/comunidad de bienes -como es el caso de ciertos complejos inmobiliarios privados del artículo veinticuatro número cuatro de la Ley 49/1960, de 21 de julio, de propiedad horizontal-será posible sustituir el referido acuerdo unánime para la modificación estatutaria por el acuerdo de la mayoría de propietarios. En este caso será igualmente posible excepcionar la regla contenida en la citada Ley canaria.

38 Como sucede con varios establecimientos de las cadenas hoteleras Ritz-Carlton, Four Seasons o Startwood, entre otras.

$39 \mathrm{Ni}$ siquiera en el caso analizado supra en relación a aquellos inmuebles pro indiviso radicados en las Islas Canarias y cuya propiedad se haya enajenado en su totalidad a una sociedad mercantil, pues a pesar de que su personalidad jurídica deberá ser en todo caso diferente -independiente- de la personalidad de la sociedad mercantil que gestione su explotación, sus titulares serán idénticos.

40 Prevalencia sobre la que mostró ciertos reparos Munar Bernat (2010: 326-327), para quien era difícil conjugar el principio de unidad de explotación y la utilización residencial de las unidades de alojamiento, si bien tales reparos fueron emitidos con anterioridad a la admisión del condo-hotel por la normativa turística autonómica.

41 Límite inexistente en Estados Unidos, por lo que los adquirentes de unidades de alojamiento en este país pueden elegir residir en ellas durante todo el año. Será el promotor el que, si así lo estima necesario, incluya en el contrato de compraventa algún tipo de limitación temporal en cuanto al uso residencial de las unidades de alojamiento. Así, por ejemplo, condo-hoteles neoyorquinos como el Trump Soho solamente admiten el uso residencial de las unidades de alojamiento por parte de sus propietarios durante un determinado número de días al año. Por el contrario, el One57 no establece ningún límite en este sentido (Polsky, (2013).

42 Condiciones ventajosas que, por su propia naturaleza, deben estar previstas en el contrato concluido con la empresa explotadora. En la Comunidad Autónoma canaria no se diferencia entre uso gratuito y en condiciones ventajosas, refiriéndose únicamente a su uso efectivo por parte de los propietarios. Para el legislador canario, que atiende únicamente al hecho de si se ha producido efectivamente un uso de la unidad alojativa por parte de sus propietarios, parece que le resulta indiferente si tal uso se ha hecho de forma gratuita o disfrutando de ciertas ventajas, por lo que en ambos casos computaría como uso residencial (como prevén, expresamente, las leyes andaluza y balear).

43 Ahondando en esta cuestión, el artículo 31.1 (Deber de atenerse al uso turístico) del Decreto 85/2015, de 14 de mayo, por el que se aprueba el Reglamento de la Ley de renovación y modernización turística de Canarias, advierte que "[...] es deber de los titulares de los establecimientos turísticos destinarlos al ejercicio de la actividad turística conforme a la calificación de uso asignada en la parcela por el planeamiento, y la del inmueble construido en ella según la licencia obtenida en el momento de su edificación en el caso de que la calificación fuera de uso mixto residencial o turístico indistintamente, así como atenerse a las limitaciones respecto al uso impuestas por el planeamiento, la legislación sectorial o el carácter convencional que le sean aplicables". En un sentido similar vid. art. 18 números 2 y 3 LTA, completada por su Disposición final segunda.

${ }_{44}$ Para ordenar este requerimiento el Decreto canario utiliza el procedimiento específico regulado en su artículo 26 para incumplimientos del deber de conservar, rehabilitar y deber de atenerse al uso efectivo de los establecimientos turísticos.

45 Sobre la inscripción en el Registro de la Propiedad de los diferentes elementos de la propiedad horizontal que componen el condo-hotel y la variada problemática vinculada con esta cuestión vid. Prada Álvarez Buyilla (2010: 333 y ss.).

46 Recuérdese que este precepto señala que "[e]l tercero que de buena fe adquiera a título oneroso algún derecho de persona que en el Registro aparezca con facultades para transmitirlo, será mantenido en su adquisición, una vez que haya inscrito su derecho, aunque después se anule o resuelva el del otorgante por virtud de causas que no consten en el mismo Registro. $[\ldots] "$. 
47 La ley andaluza añade que esta cesión debe ser permanente. No se entiende muy bien a qué se refiere el legislador andaluz cuando exige la permanencia de esta cesión, pues la duración del contrato de cesión puede estar limitado -tal y como establece la propia norma andaluza- a diez años. Quizás quiera señalar que siempre que un inmueble esté configurado como condo-hotel su uso deberá estar cedido a una empresa explotadora (con independencia de cuál sea ésta en cada momento).

48 El legislador balear incluye también a los vendedores de unidades de alojamiento.

49 El legislador canario establece un límite temporal para la entrega de este documento diferente al momento de la venta de las unidades de alojamiento: el momento de otorgamiento de la escritura de compraventa de éstas o de las participaciones indivisas del inmueble, en caso de copropiedad sobre el mismo. En tales casos resulta perfectamente posible que las partes perfeccionen el contrato de compraventa de las unidades o de las participaciones indivisas (mediante documento privado) sin que haya nacido la obligación legal de informar a los compradores de las cuestiones previstas en la norma -demorada en este supuesto al momento de la elevación a público del contrato de compraventa-, con los perjuicios que esta situación puede generarles.

50 Remitiéndose, en relación a la configuración de este documento, al desarrollo reglamentario de la ley canaria. Extremo que, salvo error u omisión, no se encuentra desarrollado en el Decreto 85/2015, de 14 de mayo, por el que se aprueba el Reglamento de la Ley de renovación y modernización turística de Canarias.

51 En tales casos el legislador balear establece la siguiente cautela: los establecimientos que enajenen la propiedad de sus unidades de alojamiento tendrán que ofrecer a los adquirentes, en los periodos en los que éstos disfrutan personalmente de su propiedad, todos los servicios de alojamiento y complementarios propios del establecimiento de alojamiento de que se trate (art. 35.2 LTIB).

52 La profesora González Cabrera (2013: 794) analiza esta previsión de la Ley canaria, así como los elementos necesarios para dicha transformación.

53 En tal sentido, si transcurrido este plazo sin que el establecimiento hubiese superado los planes de modernización y calidad establecidos al efecto, la Administración turística procederá a incoar el procedimiento para el restablecimiento de la modalidad de explotación que en origen poseía aquél. La transformación en condo-hotel no es, por tanto, definitiva.

54 En cuanto a la responsabilidad por tales infracciones, se determinan expresamente en el artículo $73 d$ ) y $e$ ) de esta Ley.

55 Ad exemplum, las unidades de alojamiento del hotel Four Seasons de la estación de esquí de Whistler (Canadá) pasaron de un precio de venta medio de un millón cien mil dólares (canadienses) en 1999 a medio millón de dólares en 2012.

56 Ad exemplum, el precio medio de la noche de hotel en la ciudad de Nueva York habría caído de los trescientos dólares anteriores a la crisis económica a los doscientos veintisiete dólares en 2010 (solo en este año abrieron sus puertas en la ciudad más de una veintena de establecimientos, lo que supuso un aumento en la oferta alojativa de más de seis mil setecientas plazas).

57 Son combo-hoteles, entre otros, The Residences en el Hotel Wiliamsburg, The Apex en el Starwood Alof Hotel o los apartamentos del 57-Story Setai Fifth Avenue (todos en la ciudad de Nueva York).

58 Restricciones temporales al uso residencial que, como se ha señalado anteriormente, no son impuestas por el ordenamiento jurídico estadounidense, sino por el promotor del condo-hotel en el contrato de compraventa de las unidades de alojamiento, si así lo estimase conveniente.

59 Tan altos pueden ser los costes de mantenimiento que algunos propietarios de unidades de alojamiento, ante la imposibilidad de enajenarlas, tienen como única solución para intentar reducirlos el cambio de empresa explotadora por otra de menos prestigio (Wittenburg, 2014).

60 Ad exemplum, el artículo 32 LTIB admite varios usos secundarios y compatibles con el uso turístico (sociocultural, docente, almacén, oficinas, religioso, sanitario, administrativo, asistencial, etc.) pero no el residencial (lo máximo que admite en este sentido es el uso residencial para personal empleado y de dirección, o de los propietarios de condo-hoteles dentro de los límites establecidos por la LTIB).

${ }_{61}$ Vid, ad exemplum, el artículo 43.1 a) LTA, cuyo contenido es reiterado por los Decretos 194/2010, de 20 de abril, que regula los establecimientos de apartamentos turisticos (art. 9.2) y 47/2004, de 10 de febrero, de establecimientos hoteleros (art. 28.2). En el mismo sentido, el artículo 39.1 a) LTIB. Sobre tales exigencias, vid. Sanz Domínguez (2006).

62 Y que, en la práctica, suelen estar abiertas al público en general en muchos establecimientos de alojamiento turístico.

63 Este autor aporta los datos de la National Association of Realtors, los cuales reflejan una subida en la venta de unidades de alojamiento de condo-hoteles en Estados Unidos de más de un 7\% en abril de 2014 (mientras que el mercado de viviendas residenciales únicamente habría subido un $0,5 \%$ en este mismo periodo).

64 En inglés en el original, traducción del autor. 